\title{
Image Tracking Berbasis Augmented Reality untuk Relasi Antara Sunnah Nabi dan Manfaat Secara Medis
}

\section{(Image Tracking Based on Augmented Reality for Relationships Between Prophet's Sunnah and Medical Benefits)}

\author{
Febrian Wahyu Christanto ${ }^{1}$, M. Fauzan Affandi ${ }^{2}$, Titin Winarti ${ }^{3}$ \\ ${ }^{1,2}$ Teknik Informatika Universitas Semarang \\ ${ }^{3}$ Sistem Informasi Universitas Semarang \\ ${ }^{1}$ febrian.wahyu.christanto@usm.ac.id
}

\begin{abstract}
Abstrak - Aplikasi yang membahas Sunnah Nabi secara khusus saat ini masih sulit dicari di Android. Beberapa aplikasi ada yang membahas tentang Sunnah Nabi tetapi masih kurang menarik karena hanya berisi tentang pengenalan Sunnah, belum ada yang membahas manfaat melaksanakan Sunnah tersebut secara terperinci, imbasnya sekarang ini banyak remaja yang kurang mengamalkan Sunnah Nabi dalam kehidupan sehari hari, padahal banyak sisi menarik dalam Sunnah, salah satunya manfaat melakukan Sunnah dalam pandangan medis. Maka diperlukan sebuah terobosan aplikasi baru yang menarik untuk mengenalkan Sunnah Nabi ditambah dengan manfaatnya secara medis dengan harapan remaja sekarang ini bisa lebih bersemangat mengerjakan Sunnah Nabi dalam kehidupan sehari - hari. Augmented Reality (AR) adalah suatu lingkungan yang memungkinkan pengguna melihat objek 3 dimensi terlihat seperti asli. Aplikasi Sunnah Nabi Plus dapat di terapkan dalam objek 3 dimensi melalui Augmented Reality (AR). Pengembangan aplikasi ini menggunakan metode pengumpulan data yang terdiri dari wawancara, observasi, dan kepustakaan. Sedangkan untuk metode pengembangan sistem menggunakan metode Prototype. Untuk implementasi aplikasi menggunakan bahasa pemrograman $\mathrm{C}$. Dari hasil implementasi aplikasi di dapatkan peningkatan pengetahuan terhadap Sunnah sebesar $52 \%$ responden menjadi mengetahui tentang Sunnah. Diharapkan aplikasi ini dapat lebih menarik minat remaja untuk mengerjakan Sunnah - Sunnah Nabi.
\end{abstract}

Kata-kata kunci: Aplikasi, Manfaat Sunnah Nabi, Manfaat Medis, Augmented Reality

Abstract - Applications that discuss the Prophet's Sunnah specifically are still difficult to find on Android. Several applications discuss the Prophet's Sunnah but are still less interesting because it only contains the introduction of the Sunnah, no one has discussed the benefits of implementing the Sunnah in detail. The impact today is that many teenagers do not practice the Prophet's Sunnah in their daily lives even though there are many interesting aspects in the Prophet's Sunnah. One of the benefits of doing the Sunnah in a medical view. So we need a breakthrough interesting new application to introduce the Prophet's Sunnah coupled with its medical benefits with the hope that today's teens can be more eager to work on the Sunnah of the Prophet in everyday life. Augmented Reality (AR) is an environment that allows users to see 3-dimensional objects that look like the original. The Sunnah Plus Plus application is implemented in 3-dimensional objects through Augmented Reality (AR) using the image tracking method. The use of the Prophet's Sunnah marker images in the form of cards will later be read by smartphone's camera as triggers to display 3-dimensional animation in this application. Data collection methods using interviews, observation, and literature. As for the method of system development using the Prototype method. For the implementation of this application using the $C$ \# programming language. From the results of the implementation of the Sunnah Plus application, it was found that the respondents' knowledge of the Sunnah increased until $52 \%$. It is hoped that this application will be more attractive to Muslim teenagers to work on the Prophet's Sunnah.

Keywords: the Prophet's Sunnah, Medical Benefits, Augmented Reality, Image Tracking

\section{PENDAHULUAN}

Sunnah nabi dalam agama Islam merupakan hal yang sangat penting dan perlu diperhatikan karena Sunnah adalah kebiasaan, ilmu, keyakinan, ucapan, dan penetapan yang ditempuh dan dilakukan oleh Rasulullah [1]. Tetapi banyak orang yang bahkan tidak mengetahui perkara Sunnah dalam kehidupan sehari-hari terutama 
pada kalangan remaja, hal ini dikarenakan media untuk mempelajari hal tersebut kebanyakan masih berbentuk buku, sehingga banyak diantara kalangan remaja yang kurang memprioritaskan waktu khusus untuk membaca buku mengenai Sunnah Nabi. Padahal ada manfaat yang sangat besar ketika sesorang melaksanakan Sunnah yang diajarkan nabi Muhammad selain mendapatkan pahala, Sunnah Nabi juga banyak yang memiliki manfaat baik untuk kesehatan yang dapat dijelaskan keilmiahannya dalam ilmu medis [2].

Di era modern ini smartphone merupakan barang yang sudah biasa dimasyarakat terutama pada kalangan remaja, banyak diantara remaja muslim yang sudah mencoba berbagai macam aplikasi [3] [4] [5] [6]. Saat ini sudah banyak aplikasi yang memuat tentang Sunnah Nabi yang mengenalkan berbagai Sunnah. Banyak aplikasi tersebut hanya terdapat banyak menu dan tulisan saja, dan beberapa diantarnya mengandung iklan terlalu banyak dan isinya lebih menekankan tentang macam macam Sunnah disertai dalil haditsnya banyak yang tidak menjelaskan mengenai manfaat dari melaksanakan Sunnah yang dimaksud. Mungkin bagi sebagian kalangan remaja akan cenderung kurang menarik [3].

Dari hasil kuesioner yang dilakukan melibatkan 100 (seratus) orang responden yaitu remaja Muslim Masjid Pesanggrahan Kota Semarang menunjukkan bahwa tingkat pengetahuan akan Sunnah Nabi sangat memprihatinkan, yaitu hanya $40 \%$ remaja yang mengetahui tentang Sunnah Nabi, 27\% hanya sedikit mengetahui, dan sisanya tidak mengetahui tentang Sunnah Nabi. Tentunya hal ini merupakan masalah yang perlu diperhatikan.

Disini diperlukan sebuah aplikasi Sunnah Nabi Plus yang menarik, menampilkan sesuatu yang baru, dan membuat pengguna aplikasi tersebut merasa rugi jika tidak mengamalkan Sunnah yang dimaksud, sehingga diharapkan dapat mengajak penggunanya menerapkan Sunnah - Sunnah Nabi dalam keseharian karena ternyata Sunnah ini juga mempunyai representasi logis di bidang medis. Sebagai contoh Sunnah Nabi untuk tidur menghadap ke kanan dapat melancarkan aliran darah [7], tidur dalam keadaan gelap dapat menghambat keluarnya hormon melatonin dimana hormon tersebut sangat bermanfaat bagi tubuh [7], makan dan minum dengan duduk dapat menghindarkan dari penyakit kristal ginjal [8], bejalan menuju ke masjid dapat melatih otot - otot dan mengefektifkan sendi-sendi [9], sunnah menutup hidung ketika bersin dapat mencegah penularan bakteri [10], sunnah bangun malam dapat mengurangi risiko terkena penyakit pembekuan darah [11].

Untuk mewujudkan penelitian ini, beberapa penelitian terdahulu mengenai relasi Sunnah dengan medis yang pernah dilakukan sebelum penelitian ini yaitu relevansi antara hadits dengan sains modern yang dapat kita temukan dalam banyak ungkapan Nabi semata-mata menjadi fakta peradaban akan kebenaran syari at yang dibawa oleh Rasulullah disampaikannya bukan dari buah pikirannya, akan tetapi bersumber dari yang Maha menurunkan kebenaran [12]. Selain itu penelitian peningkatan kualitas tidur pasien kanker payudara yang menjalani kemoterapi setelah diberikan intervensi penerapan Sunnah Rosul sebelum tidur dapat digunakan referensi dalam penelitian ini bahwa Sunnah Rosul memiliki manfaat secara medis [13]. Wudhu menjelang tidur ternyata terbukti secara efektif dapat meningkatkan kualitas tidur mahasiswa Keperawatan [14]. Penelitian tentang hikmah dianjurkannya untuk tidur miring ke kanan adalah karena dengan miring ke kanan mempunyai banyak manfaat di antarnya mengistirahatkan otak kiri, mengurangi beban jantung, mengistirahatkan lambung, meningkatkan waktu penyerapan gizi, merangsang buang air besar, menjaga kesehatan paru-paru, dan menjaga saluran pernafasan [15]. Serta penelitian desensitisasi sistematik dengan dzikir tasbih dapat berpengaruh secara signifikan dalam menurunkan simtom kecemasan pada gangguan fobia spesifik [16].

Penelitian terdahulu mengenai beberapa Sunnah nabi dan manfaatnya secara medis, diantarannya yaitu Sunnah sebelum tidur, Sunnah posisi saat tidur, Sunnah berwudhu sebelum tidur dan juga Sunnah berdzikir. Pada penelitian ini akan ditampilkan hal baru dengan mengenalkan representasi antara Sunnah dengan medis dengan menggunakan teknologi Augmented Reality (AR). Ini bertujuan agar lebih menarik minat pengguna khususnya untuk kalangan remaja dalam mempelajari Sunnah, karena dengan menggunakan teknologi Augmented Reality (AR) pengguna tidak hanya akan disajikan dengan dalil hadits dan manfaatnya dari sisi medis dalam Sunnah tersebut, tetapi juga dapat melihat animasi 3 (tiga) dimensi dari pelaksanaan Sunnah tersebut itulah keunggulan teknologi Augmented Reality (AR). Sedangkan basis Android yang akan digunakan akan memudahkan pengguna dalam menggunakan dan mengakses aplikasi Sunnah Nabi Plus hasil penelitian ini. Diharapkan dari hasil penelitian ini akan menambah presentase tingkat pengetahuan dan tingkat penggunaan Sunnah Nabi pada remaja Muslim Masjid Pesanggrahan Kota Semarang pada khususnya dan remaja Muslim di Indonesia pada umumnya.

\section{METODE}

Dalam melakukan perancangan sistem yang akan dikembangkan dapat menggunakan metode Prototype. 
Prototype bukanlah sesuatu yang lengkap, tetapi sesuatu yang harus di evaluasi dan dimodifikasi kembali. Model Prototype terdapat dalam Gambar 1.

Gambar 1 adalah tahapan dalam metode Prototype. Komunikasi yaitu analisis terhadap kebutuhan pengguna. Pada tahap ini dilakukan komunikasi dengan beberapa remaja terkait dengan rencana pembuatan aplikasi Sunnah Nabi Plus. Selanjutnya Perancangan Secara Cepat (quick design) yaitu pembuatan desain secara umum tentang gambaran Sunnah Nabi Plus untuk selanjutnya dikembangkan kembali. Pada tahap Permodelan dan Perancangan Secara Cepat dibuat sebuah desain aplikasi sederhana yang akan digunakan sebagai sebuah Prototype aplikasi Sunnah Nabi Plus yang meliputi:

\section{A. Use Case Diagram}

Use case diagram menggambarkan fungsionalitas sistem secara global. Berikut ini adalah use case yang berjalan di aplikasi Sunnah Nabi Plus pada Gambar 2.

Pada Gambar 2 use case diagram menunjukan yang dapat dilakukan user dalam sistem yaitu memilih sunnah dan melihat petunjuk. Setelah memilih Sunnah user akan secara langsung melihat penjelasan dari Sunnah yang dipilih oleh karena itu menggunakan relasi include, kemudian jika ingin melihat tampilan Augmented Reality (AR) maka user dapat melakukan deteksi gambar melalui tombol yang disediakan, maka dalam use case diagram menggunakan relasi extend karena bersifat optional. Setelah user melakukan deteksi gambar maka user akan secara otomatis melihat animasi 3 (tiga) dimensi dari Sunnah Nabi.

\section{B. Class Diagram}

Berikut adalah Class diagram ditunjukkan pada Gambar 3.

Pada Gambar 3 menunjukkan Class diagram dari aplikasi Sunnah Nabi Plus. Dalam Class diagram tersebut menunjukkan semua Class saling berhubungan, dan yang menjadi main class adalah class menu utama, dari diagram tersebut juga dapat dilihat bagaimana bentuk dari aplikasi Sunnah Nabi Plus ini.

\section{Deployment Diagram}

Berikut ini adalah gambar dari deployment diagram yang akan ditunjukan pada Gambar 4.
Pada Gambar 4 menunjukan gambar dari deployment diagram yang menggambarkan proses didalam sebuah sistem. Pada deployment diagram diatas proses yang dilakukan pertama kali adalah Augmented Reality Camera memindai image target kemudian mencari apakah ada image target tersebut terdapat didalam database Vuforia, lalu aplikasi melakukan rendering 3D image. Unity memberikan fasilitas untuk menampilkan Augmented Reality Camera, menghubungkan marker yang terdeteksi dengan database Vuforia, dan juga melakukan rendering 3D image untuk kemudian ditampilkan sebagai objek 3 (tiga) dimensi diatas marker yang terdeteksi.

Tahap berikutnya dalam metodologi adalah Konstruksi implementasi aplikasi menggunakan bahasa pemrograman C\# [18], kemudia dilanjutkan pembentukan Prototype termasuk pengujian dan penyempurnaan, dimana pada tahap ini dibangun sebuah aplikasi Sunnah Nabi Plus sederhana dengan hanya menampilkan sebuah deskripsi dan satu Augmented Reality (AR) animasi penerapan Sunnah Nabi untuk kemudian di tunjukkan kepada pengguna sebagai sebuah Prototype aplikasi Sunnah Nabi Plus.

Tahap terakhir yaitu Penyerahan Sistem prototype aplikasi dipresentasikan kepada pengguna dan dievaluasi kembali berdasarkan umpan balik yang diberikan oleh pengguna untuk kemudian dilakukan perbaikan Prototype yaitu pembuatan tipe yang sebenarnya berdasarkan evaluasi Prototype dan memproduksi aplikasi Sunnah Nabi Plus secara benar sehingga dapat digunakan. Aplikasi Sunnah Nabi Plus ini dapat menampilkan 10 (sepuluh) Augmented Reality (AR) pelaksanaan Sunnah Nabi dan dapat menampilkan deskripsi kaitan pelaksanaan Sunnah Nabi tersebut dengan ilmu medis.



Gambar 1. Model Prototype [17]

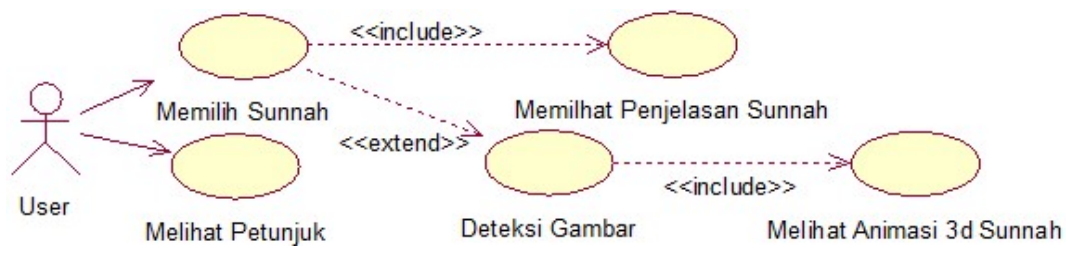

Gambar 2. Use case Diagram 


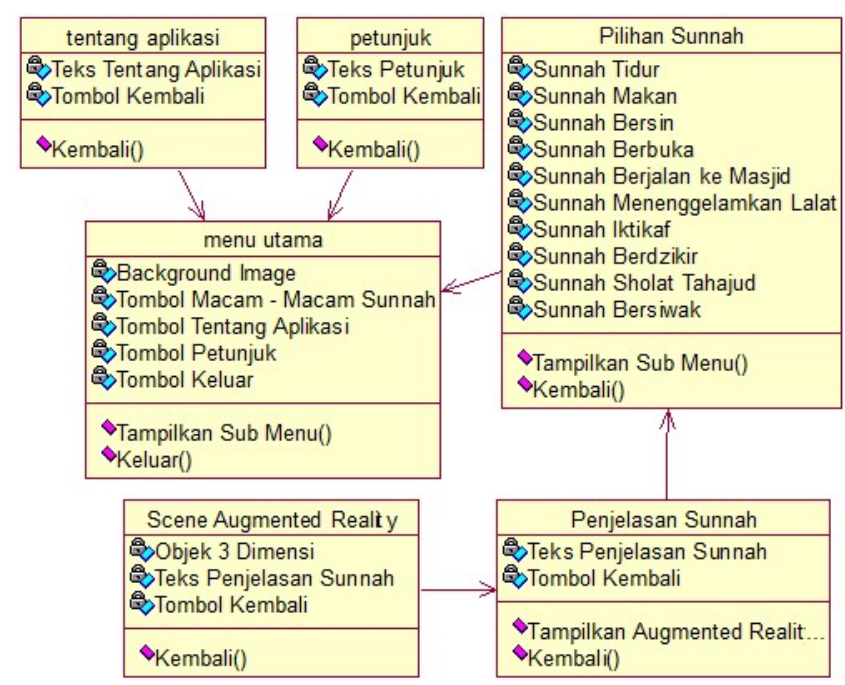

Gambar 3. Class Diagram

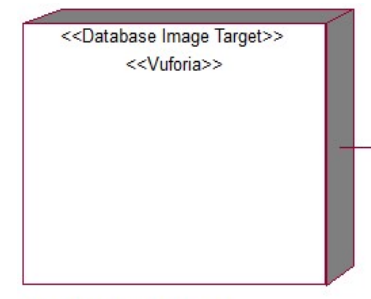

Menyimpan Gambar Target



Gambar 4. Deployment Diagram

\section{HASIL DAN PEMBAHASAN}

\section{A. Implementasi Sistem}

Wujud dari implementasi sistem ini adalah aplikasi Augmented Reality (AR) Sunnah Nabi Plus disertai dengan gambar marker Sunnah-sunnah Nabi berbentuk kartu yang nantinya akan dibaca oleh kamera smartphone. Dengan metode image tracking Augmented Reality $(A R)$ yang telah ditanam dalam aplikasi Sunnah Nabi Plus akan menghubungkan ke database aplikasi sehingga bila gambar marker yang terbaca oleh kamera smartphone cocok dengan database aplikasi, maka Sunnah Nabi Plus akan menampilkan animasi Sunnah Nabi tertentu yang berelasi dengan informasi manfaat Sunnah tersebut secara medis.

Hal pertama dilakukan yaitu pembuatan model 3 (tiga) dimensi, texturing berserta animasinya menggunakan software Blender. Blender adalah sebuah software 3D suite yang boleh dikatakan salah satu yang terlengkap diantara software open source. Tool-tool yang disediakan sederhana, namun sudah mencakup seluruh kebutuhan untuk pembuatan pemodelan 3D dan film animasi [3].
Tahap selanjutnya adalah implementasi database. Database yang digunakan adalah berupa gambar 2 (dua) dimensi yang diunggah ke halaman https://developer.vuforia.com/targetmanager. Berikut adalah beberapa marker yang digunakan untuk image tracking di tunjukkan pada Gambar 5.

Gambar 5 menunjukkan gambar marker yang akan diunggah ke dalam database Vuforia yang kemudian dilakukan import kedalam Unity untuk digunakan sebagai marker.

Pembuatan aplikasi yang terdiri dari menu, background, button, sound, dan sebagainya yang dilakukan menggunakan software Unity versi 2017.3 yang sudah mendukung Vuforia Augmented Reality (AR). Berikut adalah proses image tracking yaitu proses yang harus dilakukan jika pengguna ingin melihat tampilan animasi 3 (tiga) dimensi dari pelaksanaan Sunnah ditunjukkan pada Gambar 6.

Gambar 6 menunjukkan urutan yang harus dilakukan pengguna untuk dapat melihat tampilan Augmented Reality $(A R)$ pelaksanaan Sunnah Nabi. Tahap pertama pengguna harus masuk kedalam aplikasi Sunnah Nabi 
Plus dan memindai marker (Kartu Sunnah) sesuai dengan Sunnah Nabi yang dipilih. Pengguna dapat melihat animasi 3 (tiga) dimensi pelaksaan Sunnah Nabi. Pengguna juga dapat memperbesar dan merotasikan objek 3 (tiga) dimensi dengan menyentuh layar.

Hasil dari perancangan antarmuka menggunakan Balsamic Mockup diimplementasikan pada gambar implementasi antarmuka. Berikut ini adalah gambar dari menu utama ditunjukan pada Gambar 7.

Gambar 7 merupakan tampilan awal aplikasi setelah dijalankan yang disebut sebagai menu utama. Menu utama ini terdiri beberapa tombol yang memiliki fungsi tersendiri yaitu tombol Macam - macam Sunnah digunakan untuk menampilkan halaman menu pilihan Sunnah, dimana pengguna dapat memilih Sunnah pada menu tersebut, tombol Petunjuk digunakan untuk menampilkan petunjuk penggunaan aplikasi, sedangkan tombol Tentang Aplikasi digunakan untuk melihat halaman tentang aplikasi tersebut dibuat, dan tombol Keluar digunakan untuk keluar dari aplikasi. Berikut ini adalah gambar dari halaman macam - macam Sunnah yang akan ditunjukan pada Gambar 8 .

Gambar 8 menunjukkan antarmuka halaman macam - macam Sunnah dimana pengguna dapat memilih Sunnah yang akan dilihat penjelasannya mengenai relasinya dengan medis. Berikut ini adalah gambar dari halaman Augmented Reality Camera yang akan ditunjukan pada Gambar 9.

Gambar 9 menunjukkan tampilan 3 (tiga) dimensi pelaksanaan Sunnah tahajud beserta dengan penjelasan medisnya, untuk menyembunyikan detail penjelasan tersebut dapat menekan tombol panah, untuk kembali pengguna dapat menekan tombol Kembali ke Menu Sunnah.

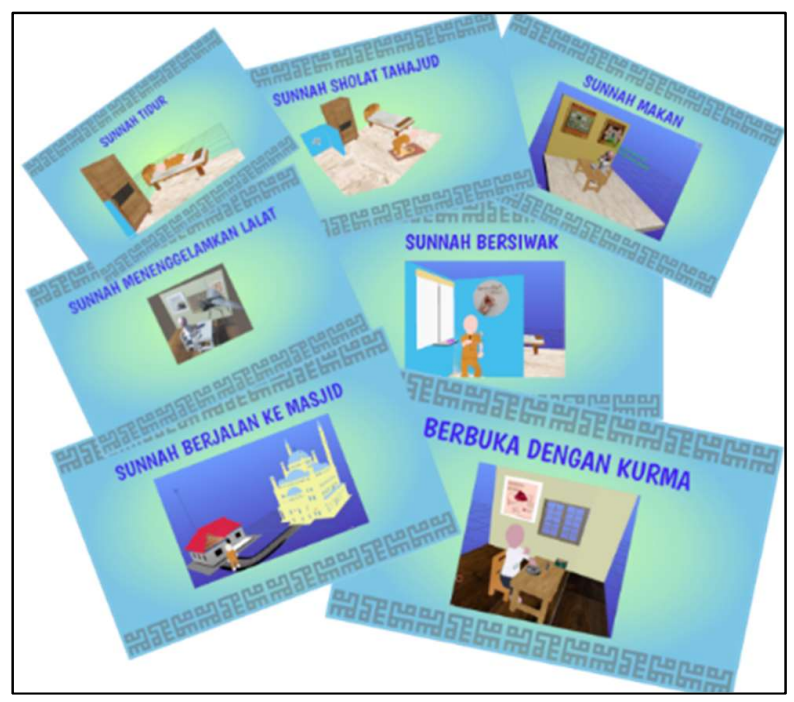

Gambar 5. Marker

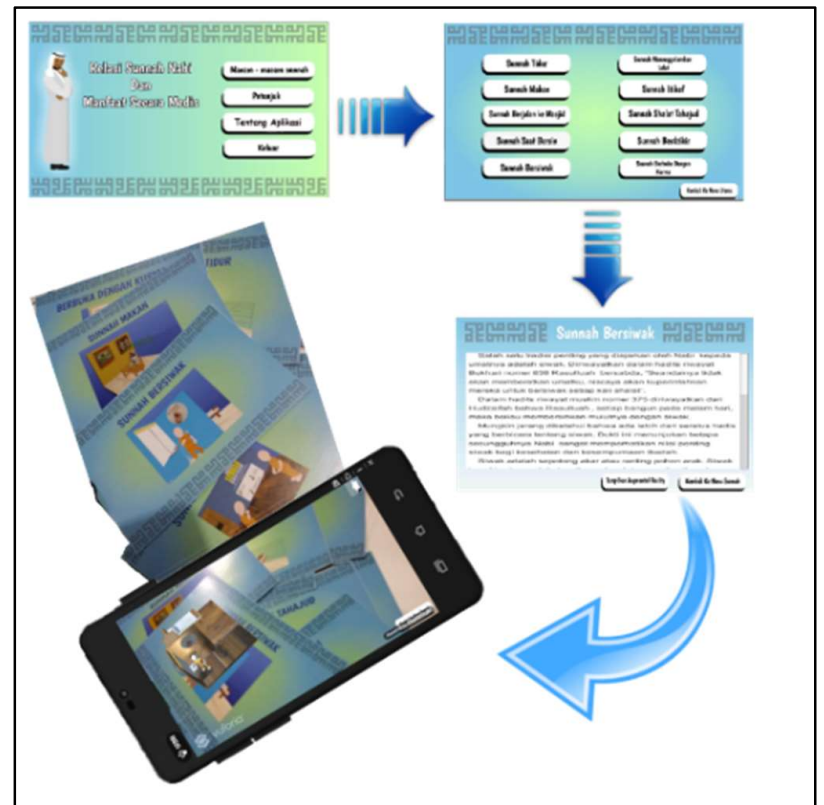

Gambar 6. Proses Image Tracking

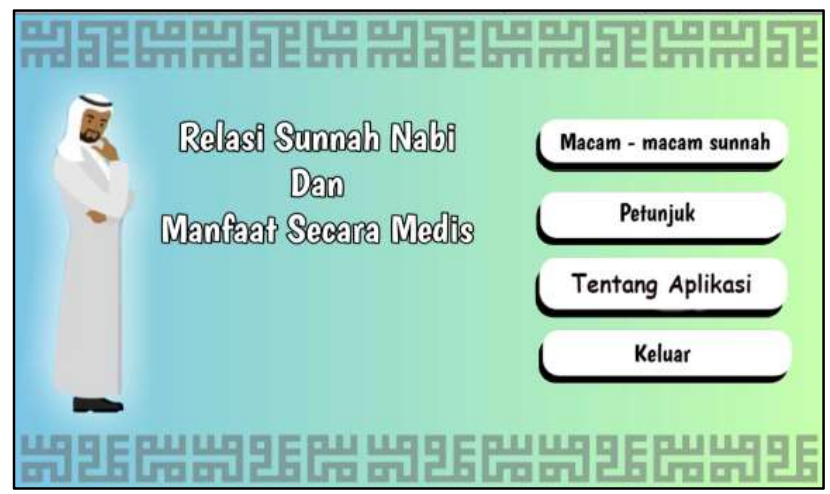

Gambar 7. Menu Utama

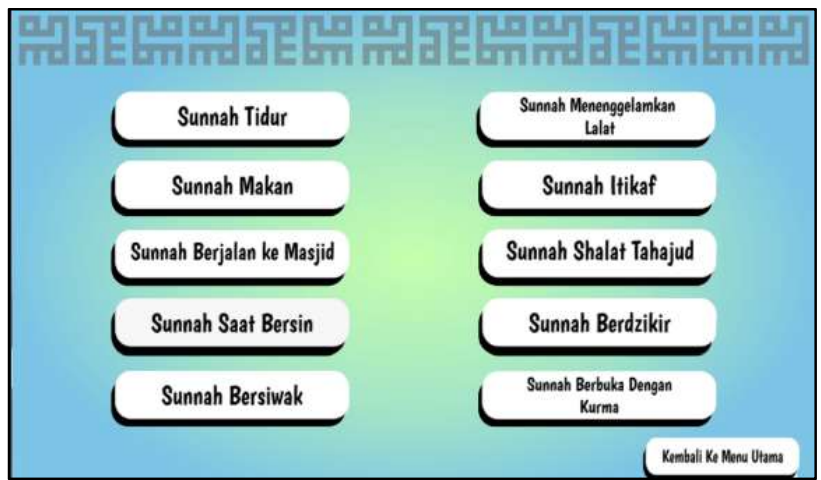

Gambar 8. Halaman Macam - Macam Sunnah 




Gambar 9. Halaman Augmented Reality Camera Sunnah Sholat Tahajud

\section{B. Pemgujian Sistem}

Pengujian sistem berguna untuk melihat sejauh mana aplikasi ini dapat berjalan dan menemukan kesalahan yang mungkin terjadi pada aplikasi. Pengujian aplikasi Augmented Reality (AR) Sunnah Nabi Plus ini menggunakan dua teknik pengujian yaitu dengan menguji sistem dengan Fungsionalitas sistem dan Kuesioner.

Dalam Pengujian Fungsionalitas sistem ini dilakukan dengan menguji aplikasi dengan menggunakan persepsi kacamata pengguna. Pengujian semua fungsi dari sistem dan kemudian mencatatnya dalam tabel. Tabel hasil pengujian dapat dilihat pada Tabel 1 .

Dari Tabel 1 dapat dilihat bahwa berdasarkan hasil pengujian yang telah dilakukan, didapati hasil bahwa setiap navigasi berjalan baik, tidak terdapat kesalahan proses dan secara fungsional mengeluarkan hasil yang sesuai dengan yang diharapkan.

Pengujian berikutnya adalah Pengujian Kuesioner yang merupakan pengujian langsung kepada pengguna untuk mencoba aplikasi dan mengisi kuesioner. Dari kuesioner tersebut akan dilakukan perhitungan untuk dapat diambil kesimpulan terhadap penilaian dari aplikasi atau sistem yang baru dibuat dan di bandingkan dengan kuesioner yang sudah didibagikan dan diisi oleh pengguna sebelum aplikasi diterapkan.

Kuesioner dibagikan kepada 100 orang pengguna aplikasi yang berisi 10 pertanyaan berskala 1 sampai dengan 3. Dari hasil pengujian yang telah dilakukan yaitu dengan pengujian perhitungan pilihan kategori jawaban dari kuesioner yang telah dibagikan menjadi dua grafik yaitu grafik untuk tingkat pengetahuan akan Sunnah dan juga grafik tingkat pelaksanaan dari Sunnah itu sendiri yang kemudian menghasilkan empat grafik yang dapat dilihat pada Gambar 10, Gambar 11, Gambar 12 dan Gambar 13.

Dari Gambar 10 dan Gambar 11 terlihat bahwa terjadi tingkat pengetahuan akan Sunnah yang sebelumnya hanya $40 \%$ yang mengetahui menjadi $92.7 \%$, sedangkan untuk tingkat pelaksanaan Sunnah terlihat pada Gambar 12 dan Gambar 13 dimana terlihat sebelum penerapan aplikasi tingkat pelaksanaan Sunnah sebesar 37.25\% menjadi $40.25 \%$, sedangkan untuk yang lebih sering dalam pelaksanaan Sunnah dari 25\% menjadi 34.5\%.

TABEL I

HASIL PENGUJIAN FUNGSIONALITAS SISTEM

\begin{tabular}{|c|c|c|c|c|}
\hline No & Kasus Uji & Langkah Uji & Hasil & Ket \\
\hline 1 & $\begin{array}{l}\text { Menampilkan } \\
\text { menu utama }\end{array}$ & $\begin{array}{l}\text { Buka aplikasi } \\
\text { Sunnah }\end{array}$ & $\begin{array}{l}\text { Menampilkan } \\
\text { menu utama }\end{array}$ & $\sqrt{ }$ \\
\hline 2 & $\begin{array}{l}\text { Buka menu } \\
\text { pilihan } \\
\text { Sunnah }\end{array}$ & $\begin{array}{l}\text { Tekan tombol } \\
\text { "Macam - } \\
\text { Macam } \\
\text { Sunnah" }\end{array}$ & $\begin{array}{l}\text { Tampil halaman } \\
\text { pilihan Sunnah }\end{array}$ & $\sqrt{ }$ \\
\hline 3 & $\begin{array}{l}\text { Buka menu } \\
\text { petunjuk }\end{array}$ & $\begin{array}{l}\text { Tekan tombol } \\
\text { petunjuk }\end{array}$ & $\begin{array}{l}\text { Tampil menu } \\
\text { petunjuk } \\
\text { penggunaan } \\
\text { aplikasi }\end{array}$ & $\sqrt{ }$ \\
\hline 4 & $\begin{array}{l}\text { Buka menu } \\
\text { tentang } \\
\text { aplikasi }\end{array}$ & $\begin{array}{l}\text { Tekan tombol } \\
\text { tentang aplikasi }\end{array}$ & $\begin{array}{l}\text { Tambil menu } \\
\text { tentang aplikasi }\end{array}$ & $\sqrt{ }$ \\
\hline 5 & $\begin{array}{l}\text { Keluar dari } \\
\text { aplikasi }\end{array}$ & $\begin{array}{l}\text { Tekan tombol } \\
\text { keluar }\end{array}$ & $\begin{array}{l}\text { Tampil kotak } \\
\text { dialog }\end{array}$ & $\sqrt{ }$ \\
\hline
\end{tabular}


Persentase Tingkat Pengetahuan Sunnah Sebelum Aplikasi

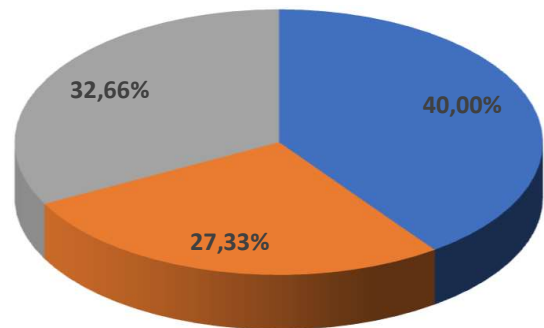

- Mengetahui $\square$ Sedikit Mengetahui Tidak Mengetahui

Gambar 10. Grafik Pengujian Tingkat Pengetahuan Sunnah Sebelum Aplikasi

Persentase Tingkat Pengetahuan Sunnah Setelah Aplikasi

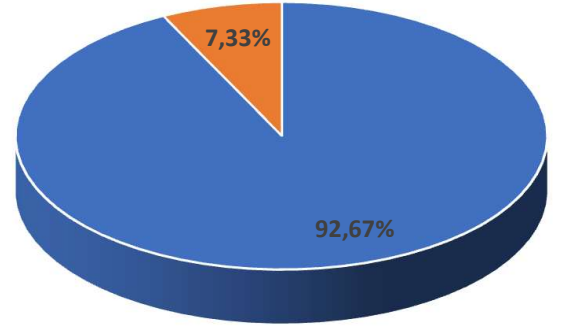

- Mengetahui = Sedikit Mengetahui = Tidak Mengetahu

Gambar 11. Grafik Pengujian Tingkat Pengetahuan Sunnah Setelah Aplikasi

Persentase Pelaksanaan Sunnah Sebelum Aplikasi



- Pernah - Kadang - kadang - Tidak Pernah

Gambar 12. Grafik Pengujian Pelaksanaan Sunnah Sebelum Aplikasi
Persentase Pelaksanaan Sunnah Setelah Aplikasi

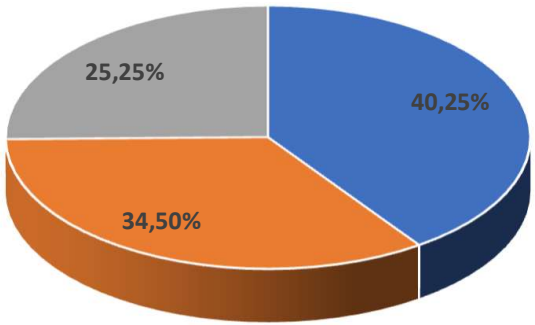

- Pernah = Kadang - Kadang $=$ Tidak Pernah

Gambar 13. Grafik Pengujian Pelaksanaan Sunnah Setelah Aplikasi

\section{PENUTUP}

Berdasarkan hasil penelitian dan pembahasan maka dapat disimpulkan bahwa Augmented Reality (AR) pada aplikasi Sunnah Nabi Plus ini membantu untuk mempelajari Sunnah Nabi dan manfaatnya secara medis terutama pada user kalangan Remaja Masjid Pesanggrahan Kota Semarang khususnya dan para remaja Muslim. User lebih tertarik mempelajari Sunnah Nabi menggunakan teknologi Augmented Reality (AR) ditunjukkan setelah penerapan aplikasi Sunnah Nabi Plus, tingkat pengetahuan akan Sunnah Nabi meningkat hingga 92\%. Terdapat peningkatan pula terhadap pelaksanaan akan Sunnah Nabi menjadi 34\% dari yang sebelumnya hanya $25 \%$. Saran yang dapat diberikan pada aplikasi Augmented Reality (AR) Sunnah Nabi Plus ini adalah ditambah lagi dengan fitur yang lebih menarik baik dari segi desain, grafis, interface, dan penambahan Sunah - Sunnah Nabi lainnya seperti Sunnah Bekam, Sunnah Minum Madu, Sunnah Mengkonsumsi Habbatus Sauda, dan sebagainya agar pengguna tidak bosan dan lebih tertarik lagi. Diperlukan juga pengembangan aplikasi ini yang serupa atau yang lebih baik lagi agar dapat berjalan pada beberapa platform yang berbeda seperti IOS, Windows Mobile, bisa juga dikembangkan ke dalam Web Base, teknologi Virtual Reality (VR), dan sebagainya.

\section{UCAPAN TERIMA KASIH}

Terimakasih kepada Fakultas Teknologi Informasi dan Komunikasi Universitas Semarang atas dukungan dana penelitian dan Remaja Masjid Pesanggrahan Kota Semarang atas dukungan dalam penggalian data sebagai bahan dalam penelitian ini. 


\section{DAFTAR PUSTAKA}

[1] KBBI, "Kamus Besar Bahasa Indonesia (KBBI)," 2018. [Online]. Available: https://kbbi.web.id/medis. [Accessed: 09-Nov-2018].

[2] T. Sutanto, The Power Of 33 Sunah Nabi Muhammad $S A W$. Yogyakarta: Pustaka Baru Press, 2015.

[3] E. Setiawan, U. Syaripudin, and Y. A. Gerhana, "Implementasi Teknologi Augmented Reality Pada Buku Panduan Wudhu Berbasis Mobile Android," J. Online Inform., vol. 1, no. 1, pp. 28-33, 2016.

[4] B. Hasyim, "Islam Dan Ilmu Pengetahuan (Pengaruh Temuan Sains terhadap Perubahan Islam)," J. Dakwah Tabligh, vol. 14, no. 1, pp. 127-139, 2013.

[5] H. Supriyono, A. . Saputra, E. Sudarmilah, and R. Darsono, "Designing hadith learning applications for android-based mobile devices," J. Inform., vol. 8, no. 2, pp. 907-920, 2014.

[6] J. Fakhri, "Sains Dan Teknologi Dalam Al-Qur'an Dan Implikasinya Dalam Pembelajaran," Ta'dib, vol. 15, no. 01, pp. 121-142, 2010.

[7] M. J. Elzaky, "Buku Pintar Mukjizat Kesehatan Ibadah," in Buku Pintar Mukjizat Kesehatan Ibadah, 1st ed., Jakarta: Zaman, 2015, p. 601.

[8] A. Nisak, Begini Caranya Hidup Sehat ala Para Nabi. Yogyakarta: DIVA Press, 2014.

[9] J. M. Az-Zaki, Sehat dengan Ibadah. Jakarta: Pustaka AL-Kautsar, 2018.

[10] Z. Naik, Miracles of Al-Qur'an \& As - Sunnah. PT.Aqwam Media Profetika, 2015.
[11] K. Irianto, Anatomi dan Fisiologi, Revisi. Bandung: Alfabeta, 2017.

[12] H. Basri, U. I. N. Sultan, and S. Kasim, "RELEVANSI ANTARA HADITS DAN SAINS KAEDAH DAN APLIKASINYA DALAM BINGKAI I JAZ ILMI," $J$. Ilm. Keislam., vol. 17, no. 1, pp. 130-146, 2018.

[13] D. Syolihan, R. Putri, S. Nabawiyati, N. Makiyah, D. Puspita, and M. Yogyakarta, "Penerapan Sunnah Rosul Sebelum Tidur Meningkatkan Kualitas Tidur Pasien Kanker Payudara," Mutiara Med. J. Kedokt. dan Kesehat., vol. 18, no. 2, pp. 61-66, 2018, doi: 10.18196/mm.180217.

[14] N. D. Lestari and M. R. Minan, "Efektivitas Terapi Wudhu Menjelang Tidur terhadap Kualitas Tidur Remaja The Effectiveness of Wudhu Therapy before Bedtime into Sleep Qualtiy in Teenagers," J. Kedokt. dan Kesehat., vol. 18 , no. 2, pp. 49-54, 2018, doi: 10.18196/mm.180215.

[15] M. Sholechah, "Posisi Tidur dalam Tinjauan Hadits ( Kajian Ma ' anil Hadits )," J. Intelekt., vol. 5, no. 2, pp. 145-152, 2016.

[16] R. Azmarina, "DESENSITISASI SISTEMATIK DENGAN DZIKIR TASBIH UNTUK MENURUNKAN SIMTOM KECEMASAN PADA GANGGUAN FOBIA SPESIFIK," J. Humanit., vol. 12, no. 2, pp. 90-104, 2015.

[17] R. S. Pressman, Rekayasa Perangkat Lunak, 7f ed. Yogyakarta: Andi, 2012.

[18] R. Roedavan, Unity Tutorial Game Engine. Bandung: Informatika, 2014. 